\title{
Aligning Method with Theory: A Comparison of Two Approaches to Modeling the Social Determinants of Health
}

\author{
Patricia O’Campo • Marcelo Urquia
}

Published online: 20 December 2011

(c) The Author(s) 2011. This article is published with open access at Springerlink.com

\begin{abstract}
There is increasing interest in the study of the social determinants of maternal and child health. While there has been growth in the theory and empirical evidence about social determinants, less attention has been paid to the kind of modeling that should be used to understand the impact of social exposures on well-being. We analyzed data from the nationwide 2006 Canadian Maternity Experiences Survey to compare the pervasive disease-specific model to a model that captures the generalized health impact (GHI) of social exposures, namely low socioeconomic position. The GHI model uses a composite of adverse conditions that stem from low socioeconomic position: adverse birth outcomes, postpartum depression, severe abuse, stressful life events, and hospitalization during pregnancy. Adjusted prevalence ratios and $95 \%$ confidence intervals from disease-specific models for low income $(<20,000 /$ year $)$ compared to high income ( $\geq 80,000 /$ year) ranged from a low of $1.43(1.09-1.85)$ for adverse birth outcomes to a high of 5.69 (3.59-8.84) for stressful life events. Estimates from the GHI model for experiencing three to five conditions yielded a prevalence ratio of $18.72(9.29-35.77)$ and a total population
\end{abstract}

P. O’Campo $(\square) \cdot$ M. Urquia

Centre for Research on Inner City Health, The Keenan Research

Centre in the Li Ka Shing Knowledge Institute, St. Michael's

Hospital, 30 Bond St, Toronto, ON M5B 1W8, Canada

e-mail: pat.ocampo@utoronto.ca

P. O'Campo

Dalla Lana School of Public Health, University of Toronto,

Toronto, ON, Canada

P. O'Campo

Department of Population, Reproductive and Family Health,

Johns Hopkins Bloomberg School of Public Health,

Baltimore, MD, USA attributable fraction of $78 \%$. While disease-specific models are important for uncovering etiological factors for specific conditions, models that capture GHIs might be an attractive alternative when the focus of interest is on measuring and understanding the myriad consequences of adverse social determinants of health.

Keywords Social determinants - Socioeconomic position · Health inequalities · Pregnancy · Birth · Biomedical model · Multinomial regression · Generalized health impact

$\begin{array}{ll}\text { Abbreviations } \\ \text { CI } & \text { Confidence intervals } \\ \text { GHI } & \text { Generalized health impact } \\ \text { LICO-AT } & \text { Low income after-tax cut-off } \\ \text { MES } & \text { Maternity Experiences Survey } \\ \text { OR } & \text { Odds ratio } \\ \text { PAF } & \text { Population attributable fraction } \\ \text { PR } & \text { Prevalence ratio } \\ \text { SEP } & \text { Socioeconomic position }\end{array}$

\section{Introduction}

Socioeconomic disparities in health have been well documented since the birth of epidemiology and public health in the mid nineteenth century [1]. The "eras" of epidemiology reflect the evolution of the disease-specific model, from the pursuit of a single cause (i.e., the germ theory) of infectious diseases, to the consideration of myriad causes (i.e., the web of causation) of specific conditions with the rise of chronic diseases as the major public health threat $[2,3]$. And while much of the focus of epidemiology is on etiologic contributors to single specific health conditions or 
behaviors (e.g., cardiovascular diseases, obesity, adequacy of prenatal care), social epidemiology has taken a specific interest in the myriad health consequences of social exposures (e.g., low income or poverty, ethnic density of neighborhoods, immigration, discrimination) [4-12].

Theoretical perspectives from the social sciences such as medical sociology suggest that the effects of social exposures such as socioeconomic position (SEP) are fundamental causes of poor health and do not cause a single health outcome but, rather, have a generalized impact on well-being [13, 14]. Evidence supporting this perspective includes the persistence and concentration of morbidity and mortality among the poor compared to wealthier populations across the centuries despite major shifts in the major causes of death during this time from infectious diseases to chronic conditions $[15,16]$. The resurgence of interest in social conditions within epidemiology in recent decades [5, 17] may have deepened our understanding of the relationships between social position and health but did so while remaining attached to the disease-specific analytic approach pervasive within epidemiology. The diseasespecific approach of identifying etiologic factors-both biological and social-is appropriate when a particular condition or problem is of interest, for example, to uncover the primary determinants of smoking during pregnancy to design effective interventions. But when the primary focus is on a social exposure (e.g., poverty, discrimination) and its impact on overall health or well-being, the diseasespecific model is theoretically incompatible with this research agenda. The disease-specific modeling of fundamental social conditions may mis- or underestimate their impact on health $[14,16,18]$.

In practice, the disease-specific model treats all potential causes (predictors) as if they had the same ontological status. However, SEP differs in several aspects from other more proximate determinants commonly studied in epidemiology, such as tobacco smoking, diet, environmental contaminants or genes. First, SEP may lead directly and indirectly to ill health through several complex pathways that change and evolve over time with the history of a given society [16]. Social organization is thus seen as a "distal", "upstream", or "fundamental" force that put individuals at "risk of risks" [15, 16, 19]. Second, as noted earlier, the effects of social organization on health are nonspecific $[14,20]$. Third, the negative effects of low social position accumulate longitudinally (i.e., the longer the exposure the greater the risk) and cluster cross-sectionally (i.e., individuals at the bottom of the social scale are more likely to experience multiple adverse outcomes) [15]. These considerations suggest that the disease-specific approach of studying only one disease manifestation of social determinants prevents us from capturing the full impact of social causes on health $[14,16,18]$. And while there are times when researchers with an exclusive interest on multifactoral determinants of a single health condition should rely on the disease-specific model, the growing interest in social disparities with a primary focus on social determinants of well-being would benefit from the use of alternative models that facilitate evaluation of a generalized effect of social factors on outcomes [14, 18].

We draw from the sociological literature which distinguishes two types of models, etiologic or disease-specific models and consequences models or models that measure the generalized impact of a particular social exposure. Models that examine the consequences or generalized impact of social exposures have as their point of departure the social cause, not the disease [6, 14, 18, 21-23]. While the conceptual or theoretical underpinnings of the two models are quite different, the operational distinctions are quite simple and focus on the outcome variable [14, 18]. While the disease-specific model uses a single health outcome, models of the consequences of social exposures use a composite outcome. Use of composite outcomes is not new to the field of health [24-26]. In the case of the study of the consequences of social exposures, the composite outcome must be grounded in sound theory; those conditions included in the dependent variable should have solid evidence supporting its relation to the social exposure of interest. Despite its promise, models of the generalized health impact (GHI) of social exposures have been applied by social scientists in studies on mental health [14, 18, 27] but have not been widely applied by epidemiologists.

Our objective was to apply the (GHI) model to the study of maternal and newborn well-being using a national survey of Canadian childbearing women and to compare it with the traditional disease-specific approach of examining one outcome at a time. Reproductive health may be suitable for this endeavour since social disparities have been amply demonstrated for multiple pregnancy related outcomes [8, 28].

\section{Methods}

\section{Study Population}

The Maternity Experiences Survey (MES) is a populationbased survey conducted by Statistics Canada during 2006-2007 on behalf of the Public Health Agency of Canada. The MES target population consisted of biological mothers who were age 15 and older at the time of their babies' singleton live birth in Canada and lived with their infants at the time of the survey [29, 30]. A stratified simple random sample was selected without replacement, using recent births drawn from the Census 2006 sampling frame. The sample was stratified on province or territory 
in which the mother resided at the time of the census and on maternal age ( $<20$ years, $\geq 20$ years). Among 8,542 women selected from the frame, 8,244 were estimated to be eligible cases based on the target criteria. The questionnaire was successfully completed by 6,421 women (77.9\% response rate). After applying the survey weights, which were adjusted for non-response, these women represented approximately 76,500 Canadian women [30]. The data were collected in a $45 \mathrm{~min}$ computer-assisted telephone interview by professional female interviewers in English, French and 13 non-official languages. Paper versions were used when telephone interviews were not feasible [30]. Information on postal code of the respondent was used to link the data to the 2006 Canadian census to characterize residential neighborhood. Further details of the survey design and methods have been reported elsewhere [30-34].

\section{Outcome Measures}

To compare the disease-specific and the social consequences models, we chose a priori several conditions that were strongly associated with high levels of deprivation and low SEP [7, 28, 35-40].

a. Adverse birth outcomes was a composite measure defined by the presence of low birthweight $(<2,500 \mathrm{~g})$, preterm birth (<completed 37 weeks) or small for gestational age (birthweight below the 10th percentile of a Canadian population-based sex- and gestational age-specific reference) [41]. These measures were constructed based on maternal reports of gestational age, infant sex and birthweight. The resulting rates of singleton preterm birth and small for gestational age in the survey were consistent with national surveillance data based on birth certificates [29].

b. Postpartum Depression was assessed using the Edinburgh Post-Natal Depression Scale, a ten item screening tool to identify postpartum depression at the time of its administration [42]. A score of 13 or more out of a maximum possible of 30 was used to indicate the presence of postpartum depression. Validation studies have showed that the scale can detect depression in postpartum women with $86 \%$ sensitivity and $78 \%$ specificity [43, 44].

c. Serious abuse was defined as the combination of threats and physical or sexual abuse suffered right before, during or after pregnancy. The MES contained a section to assess abuse and violence. The questions were adapted from the Violence Against Women Survey [45] to capture abuse and violence during the childbearing year. Threats or potential hurting acts were defined by the occurrence of direct threats of physical harm, throwing objects at them and being pushed, grabbed or shoved in a way that could have hurt respondents. Physical or sexual abuse included at least one episode of slapping, kicking, hitting with a weapon, beating, choking, use of a gun or knife, and being forced into unwanted sexual activity. Thus, serious abuse involves at least two episodes of violence of different kinds.

d. Hospitalization during pregnancy was defined as an affirmative answer to the question of whether respondents stayed at a hospital overnight before labour and the birth.

e. Frequent stressful life events were considered as such when respondents identified three or more stressful events (out of 13) in the 12-month period before the baby's birth [32].

In the disease-specific models, each of the previous conditions is considered as a separate outcome. In contrast, to be consistent with the theory underpinning the GHI models we created a compound outcome variable by counting the number of conditions experienced by respondents [18, 24, 25, 27], and categorizing them into 0 , 1,2 and $3-5$ conditions.

\section{Exposures}

a. Total household income, before taxes and deductions, of all household members from all sources in the 12-month period preceding the interview. The unexposed group was considered to be composed of households with annual incomes of 80,000 dollars and higher and exposed groups were those in the income brackets of $<20,000,20,000-49,999$, 50,000-79,999 dollars, and unknown income.

b. Neighborhood deprivation was a contextual variable assessed by the proportion of households whose income in 2005 was below the Statistics Canada Low income after-tax cut-off (LICO-AT) [46]. The LICOAT identifies households spending 20 percentage points more of their after-tax income than the average family in the region on food, shelter and clothing, thus leaving less income available for other expenses such as health, education, transportation and recreation. The LICO-AT cut-offs are differentiated by size of family and area of residence. Proportions of LICO-AT were computed at the dissemination area level, which is the smallest standard geographic area for which all census data are disseminated, with a population of 400-700 persons [46].

c. Immigrant status was categorized into Canadian-born, recent immigrants ( $<10$ years of stay in Canada), and long term immigrants ( $\geq 10$ years of stay). 
Variables for confounder control were maternal age, parity, and place of residence [46]. For the latter, place of residence was categorized into urban areas (Census Metropolitan Areas [CMA] and Census Agglomerations [CA], with an urban core of at least 10,000 inhabitants) and rural areas (non CMA/CA zones), following the Statistics Canada Standard Geographical Classification. [47]. Levels of these variables are specified in Table 1.

\section{Analytic Methods}

Survey weights were used to account for the unequal probabilities of selection of respondents and thus obtain unbiased point estimates representative of the Canadian population. Special procedures for the analysis of survey data (SURVEYFREQ and SURVEYLOGISTIC) (SAS version 9.2, SAS Institute Inc., Cary, NC) were used to obtain weighted proportions and Odds Ratios (OR) with $95 \%$ confidence intervals $(95 \% \mathrm{CI})$ using the Taylor Series method of variance estimation [48].

For modeling the five disease-specific conditions, the logistic model was used to compute ORs for each condition separately. To model the generalized impact of social exposures, and to take into account the multiple categories of our compound outcome, we used the multinomial model to obtain ORs for the occurrence of one, two, and three to five conditions, relative to none. The general regression equation of the multinomial model with a single predictor is given by $\log \left(\pi_{\mathrm{j}} / \pi \mathrm{J}\right)=\alpha_{\mathrm{j}}+\beta_{\mathrm{j}} \mathrm{x}$, where the response levels are $\mathrm{j}=1, \ldots, \mathrm{J}-1$ and the baseline response category is $\mathbf{J}$.

To avoid overestimating relative risks, odds Ratios were converted to Prevalence Ratios (PR) using a simple formula that provides a good approximation to estimates of

Table 1 Characteristics of the Maternity Experiences Survey respondents, 2006-2007, (weighted N = 71,395) by number of composite health conditions

\begin{tabular}{|c|c|c|c|c|c|c|c|c|c|c|}
\hline & \multirow{2}{*}{\multicolumn{2}{|c|}{ Total sample }} & \multicolumn{8}{|c|}{ Composite heath conditions } \\
\hline & & & \multicolumn{2}{|c|}{0 conditions $^{\mathrm{b}}$} & \multicolumn{2}{|c|}{1 condition $^{\mathrm{b}}$} & \multicolumn{2}{|c|}{2 conditions $^{\mathrm{b}}$} & \multicolumn{2}{|c|}{$3-5$ conditions $^{\mathrm{b}}$} \\
\hline & $\mathrm{N}^{\mathrm{a}}$ & $(\%)$ & $\mathrm{N}^{\mathrm{a}}$ & $(\%)$ & $\mathrm{N}^{\mathrm{a}}$ & $(\%)$ & $\mathrm{N}^{\mathrm{a}}$ & $(\%)$ & $\mathrm{N}^{\mathrm{a}}$ & $(\%)$ \\
\hline Total respondents & 71,395 & $(100)$ & 42790 & $(59.9)$ & 19822 & $(27.8)$ & 6913 & $(9.7)$ & 1871 & $(2.6)$ \\
\hline \multicolumn{11}{|l|}{ Age group } \\
\hline$<20$ years & 1,995 & $(2.8)$ & 559 & $(1.3)$ & 706 & (3.6) & 460 & $(6.7)$ & 271 & $(14.5)$ \\
\hline $20-24$ years & 9,149 & $(12.8)$ & 3711 & $(8.7)$ & 3181 & $(16.0)$ & 1587 & $(23.0)$ & 670 & $(35.8)$ \\
\hline $25-29$ years & 20,321 & $(28.5)$ & 12871 & $(30.1)$ & 5474 & $(27.6)$ & 1561 & $(22.6)$ & 415 & $(22.2)$ \\
\hline 30-34 years & 23,904 & $(33.5)$ & 15385 & $(36.0)$ & 6329 & $(31.9)$ & 1928 & $(27.9)$ & 262 & $(14.0)$ \\
\hline$\geq 35$ years & 16,026 & $(22.4)$ & 10264 & $(24.0)$ & 4132 & $(20.8)$ & 1377 & $(19.9)$ & 253 & $(13.5)$ \\
\hline No previous live birth & 31,901 & $(44.7)$ & 18314 & $(42.8)$ & 9413 & $(47.5)$ & 3235 & $(46.8)$ & 940 & $(50.2)$ \\
\hline \multicolumn{11}{|l|}{ Household income } \\
\hline$<\$ 20,000$ & 6,039 & $(8.5)$ & 1977 & (4.6) & 2221 & (11.2) & 1215 & $(17.6)$ & 626 & $(33.5)$ \\
\hline$\$ 20,000-49.999$ & 18,948 & $(26.5)$ & 9883 & $(23.1)$ & 6008 & (30.3) & 2384 & $(34.5)$ & 673 & $(36.0)$ \\
\hline$\$ 50,000-79.999$ & 19,759 & $(27.7)$ & 12934 & $(30.2)$ & 4792 & $(24.2)$ & 1712 & $(24.8)$ & 321 & $(17.2)$ \\
\hline$\geq \$ 80,000$ & 23,042 & (32.3) & 16311 & $(38.1)$ & 5501 & $(27.8)$ & 1106 & $(16.0)$ & 125 & $(6.7)$ \\
\hline Unknown & 3,607 & (5.1) & 1685 & $(3.9)$ & 1300 & (6.6) & 496 & $(7.2)$ & 126 & $(6.7)$ \\
\hline \multicolumn{11}{|c|}{ Neighborhood deprivation } \\
\hline$<5 \%$ & 25,693 & $(36.0)$ & 16621 & $(38.8)$ & 6546 & $(33.0)$ & 2000 & $(28.9)$ & 526 & $(28.1)$ \\
\hline $5-14.9 \%$ & 28,085 & (39.3) & 16548 & $(38.7)$ & 8150 & (41.1) & 2710 & $(39.2)$ & 677 & $(36.2)$ \\
\hline $15-24.9 \%$ & 9,606 & $(13.5)$ & 5683 & $(13.3)$ & 2629 & $(13.3)$ & 985 & $(14.2)$ & 309 & $(16.5)$ \\
\hline$\geq 25 \%$ & 8,011 & $(11.2)$ & 3938 & $(9.2)$ & 2497 & (12.6) & 1218 & (17.6) & 359 & (19.2) \\
\hline Rural residence & 12,196 & $(17.1)$ & 7044 & $(16.5)$ & 3463 & $(17.5)$ & 1338 & (19.4) & 352 & $(18.8)$ \\
\hline \multicolumn{11}{|l|}{ Immigrant status } \\
\hline Canadian-born & 55,004 & (77.1) & 33115 & $(77.4)$ & 14852 & (74.9) & 5387 & (77.9) & 1650 & $(88.2)$ \\
\hline Immigrant $<10$ years & 9,162 & $(12.8)$ & 5348 & $(12.5)$ & 2834 & (14.3) & 877 & $(12.7)$ & 104 & (5.6) \\
\hline Immigrant $\geq 10$ years & 7,229 & $(10.1)$ & 4327 & $(10.1)$ & 2136 & $(10.8)$ & 649 & $(9.4)$ & 117 & (6.3) \\
\hline
\end{tabular}

a Weighted number of women

${ }^{b} 0,1,2$, and 3 or more conditions represent categories of the composite outcome

${ }^{c}$ Measured as proportion of households in a dissemination area living at or below the Statistics Canada Low Income Cutoff (LICO) 
the relative risk when direct estimation is not feasible [49]. In the formula $\mathrm{PR}_{\mathrm{i}}=\left(\mathrm{P}_{\mathrm{i}} / \mathrm{P}_{0}\right)=\mathrm{OR}_{\mathrm{i}} /\left[\left(1-\mathrm{P}_{0}\right)+\right.$ $\left.\left(\mathrm{P}_{0} \times \mathrm{OR}_{\mathrm{i}}\right)\right], \mathrm{P}_{\mathrm{i}}$ is the weighted proportion of cases in the exposure level $\mathrm{i}, \mathrm{P}_{0}$ is the weighted proportion of cases among the non-exposed and $\mathrm{OR}_{\mathrm{i}}$ is the $\mathrm{OR}$ for exposure level $\mathrm{i}$. This conversion further allowed comparing the disease specific and social consequence models in terms of population attributable fractions (PAF), based on the weighted proportion of cases at each exposure level and on the adjusted PRs, as expressed in the formula PAF $=$ $\left(\mathrm{Pd}_{\mathrm{i}}{ }^{*}\left(\left(\mathrm{PR}_{\mathrm{i}}-1\right) / \mathrm{PR}_{\mathrm{i}}\right)\right)$, where $\mathrm{Pd}_{\mathrm{i}}$ is the weighted proportion of cases in stratum $i$ and $P_{i}$ is the adjusted $P R$ in stratum i [50]. PAFs facilitated the comparison of the etiologic fraction attributed to low SEP between the diseasespecific and GHI models.

Missing data were very low for most variables and therefore were not considered in the analyses, with the exception of household income, for which we created a category labelled "Unknown" to prevent a significant drop in the sample size.

The study was approved by the St. Michael's Hospital Research Ethics Board and by the Research Data Centre Access Granting Committee of Statistics Canada.

\section{Results}

Among the 6,421 respondents in the MES, 406 women (6.3\%) were excluded due to missing or invalid responses in at least one of the outcomes or covariates. The final sample for analyses was 6,015 (weighted $\mathrm{N}=71,400$ ).

About four out of 10 women had at least one adverse condition (Table 1). Among affected women, $70 \%$ had only one and seven percent three to five outcomes. The proportion of women experiencing at least one outcome decreased with advanced age, higher household income and lower neighborhood deprivation. This pattern was more evident as the number of concomitant conditions increased. Among affected women, the number of concomitant conditions increased while the proportion of immigrants decreased.

Regression models for each single condition showed moderate to strong associations between low household income and each outcome, with PR ranging from 1.4 to 5.7, after adjustment (Table 2). In comparison, the multinomial model showed two types of gradients; the well-known gradient by which the lower the income the poorer the outcomes, and a new gradient by which, within each exposed income group, the PR increase with the number of conditions, reaching a prevalence ratio of 17 for women in the lowest income households having 3-5 conditions. The prevalence of 3-5 conditions was $10.36 \%$ among women living in households making $<20,000$ dollars $(626 / 6,039$ from Table 1) versus $0.54 \%$ among those whose household income was 80,000 or above $(125 / 23,042$ from Table 1$)$.

In the fully adjusted model, neighborhood deprivation was not consistently associated with the outcomes.

In contrast to the findings for the socioeconomic exposures, logistic models show that being an immigrant was associated with higher risk of postpartum depression but lower risk of abuse, hospitalizations and stressful life events, particularly among recent immigrants. Multinomial models show a trend towards lower risk of concomitant adverse outcomes, particularly among recent immigrants.

Another approach to compare the magnitude of effects is to examine the Population Attributable Fraction (PAF) for the social exposures. Here we show PAFs for income. Low income PAFs ranged from 15 to $55 \%$ for single conditions based on the single outcome model (Table 3). In comparison, PAFs in the composite condition model were substantially larger at 51 and $78 \%$ for 2 and 3-5 conditions, respectively.

\section{Discussion}

To our knowledge, this is the first study to apply the GHI approach to model pregnancy related outcomes. In a representative sample of Canadian childbearing women, we found that, compared to the disease-specific model, a GHI model detects stronger effects of social position on pregnancy related outcomes. Both approaches showed the well documented gradient of decreasing risk with increasing household income. In addition, we were able to demonstrate a strong dose-response relationship using the GHI model. The stronger gradient is explained, in part, by having fewer individuals with conditions related to low SEP in the 'condition free' category of the GHI model which is not true for the disease specific models.

Immigrants also exhibited linear trends according to the number of adverse outcomes, but in contrasting directions. Even after controlling for household and neighborhood income, immigrants were less likely to experience multiple conditions, particularly recent immigrants. This observation is consistent with the "healthy migrant effect" and also suggestive of its loss with increasing time spent in the new country [51].

Strengths of our study are the use of a high-quality nationally representative survey and the simultaneous consideration of a wide array of adverse outcomes. Such approaches are particularly relevant for research focussing on social determinants for example in the study of social disparities $[6,23,52]$. Our findings are strengthened by the existence of a dose-response relationship between lower income and increasing number of adverse outcomes. Although we focused our attention on household income, 


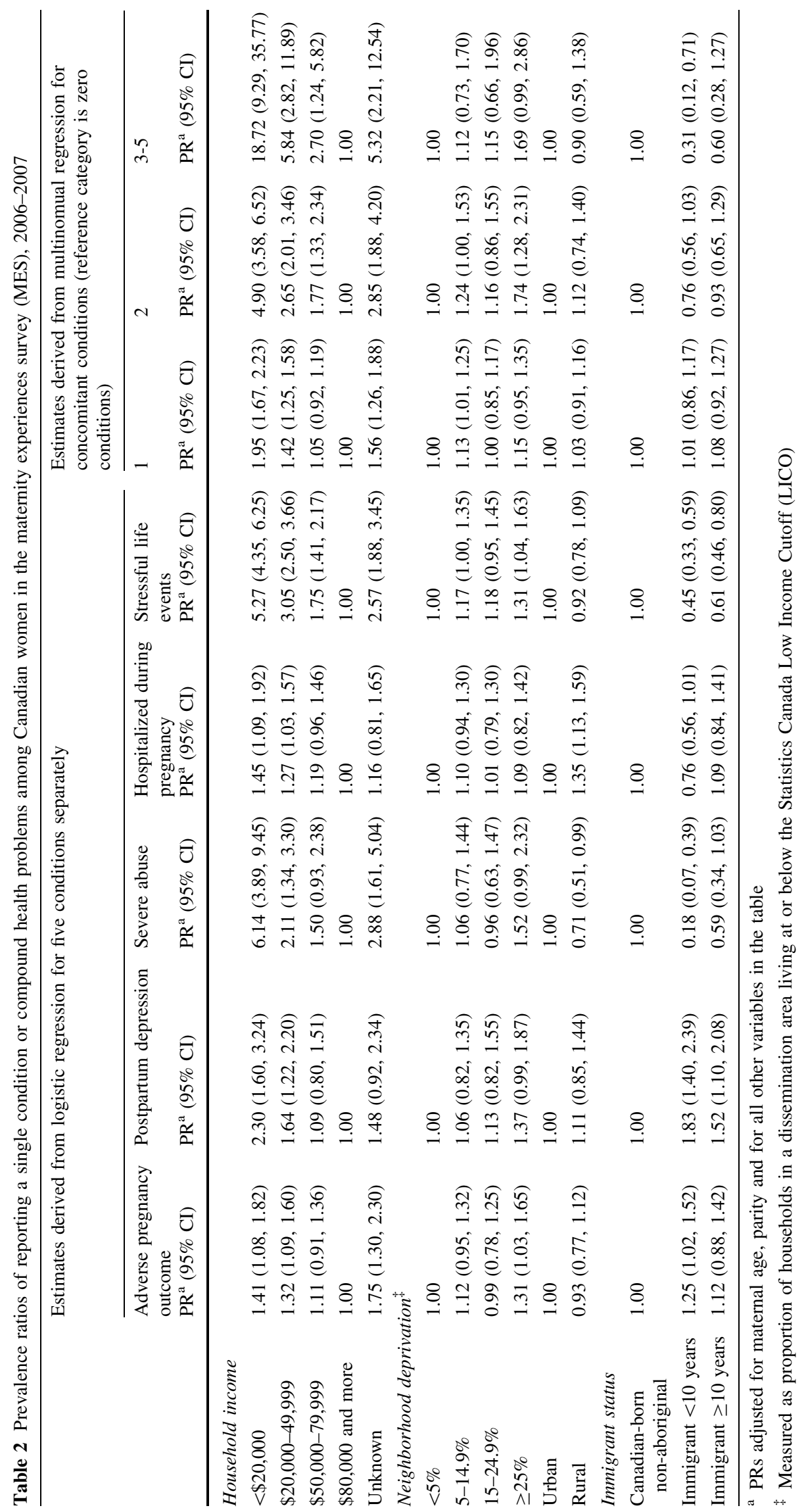


Table 3 Population attributable fractions (PAF) for single conditions or number of concomitant conditions among women in the Canadian Maternity Experiences Survey, 2006-2007

\begin{tabular}{|c|c|c|c|c|c|c|c|c|}
\hline \multirow[b]{2}{*}{ Household income } & \multicolumn{5}{|c|}{ PAF for single conditions } & \multicolumn{3}{|c|}{ PAF for concomitant conditions } \\
\hline & $\begin{array}{l}\text { Adverse } \\
\text { birth } \\
\text { outcomes }\end{array}$ & $\begin{array}{l}\text { Postpartum } \\
\text { depression }\end{array}$ & $\begin{array}{l}\text { Severe } \\
\text { abuse }\end{array}$ & $\begin{array}{l}\text { Hospitalized } \\
\text { during } \\
\text { pregnancy }\end{array}$ & $\begin{array}{l}\geq 3 \text { stressful } \\
\text { life events }\end{array}$ & 1 & 2 & $3-5$ \\
\hline$<\$ 20,000$ & 0.032 & 0.095 & 0.269 & 0.036 & 0.175 & 0.055 & 0.140 & 0.317 \\
\hline$\$ 20,000-49,999$ & 0.074 & 0.133 & 0.150 & 0.064 & 0.249 & 0.090 & 0.215 & 0.298 \\
\hline$\$ 50,000-79,999$ & 0.025 & 0.017 & 0.061 & 0.044 & 0.092 & 0.012 & 0.108 & 0.108 \\
\hline Unknown & 0.034 & 0.022 & 0.056 & 0.008 & 0.038 & 0.024 & 0.047 & 0.055 \\
\hline Total sample & 0.164 & 0.267 & 0.535 & 0.152 & 0.554 & 0.179 & 0.509 & 0.778 \\
\hline
\end{tabular}

which cannot capture the full complexity of social location $[19,52]$, we also considered additional indicators, such as immigration, which was also associated with the compound outcome in a dose-response fashion.

Several weaknesses exist. First, as data are self-reported, recall bias is always a possibility. However, our variables focused on the 2-year period preceding the interview and bias resulting from inaccurate recall is likely to be small. Second, the main exposure was total household income since disposable income after application of redistributive policies was not available in the survey, which would be more accurate as a measure of the material resources actually available to the households. The use of pre-tax income is likely to bias the estimates toward the null, yet we found strong and consistent associations. It is unlikely that reverse causation could explain our findings as prospective studies suggest that the cross-sectional associations between income and health chiefly reflect the influence of income on health rather than the opposite [13, 53]. Unfortunately, we did not have life course data to fully explore the problem of reverse causation. In the case of immigrant status, it is a fixed attribute that cannot be affected by the outcomes. Third, our list of outcomes and exposures is not exhaustive and we were constrained by what we could include by the survey. With regard to outcomes, we chose a priori a limited number of known consequences of low individual and neighborhood SEP for comparison purposes but the use of a different set of outcomes may result in different effect estimates. We anticipate that, if low SEP is associated with each single outcome, the use of the GHI model would reveal similar patterns. Moreover, the GHI approach is well suited for documenting the impact of social determinants on well being but may be less appropriate for revealing the mechanisms or pathways by which social factors result in adverse health given the outcome is a composite of many variables, some of which may have unique pathways resulting from deprivation. We did not control for correlates of income, such as maternal education and marital status, because of potential overcontrol or colinearity issues. Adjustment for smoking and substance use was discarded since these are conceptualized as mediators of the relationship of interest [8]. Finally, while we used logistic and multinomial regression, alternative approaches, such as structural equation modeling might have been employed to explore the same research questions. We anticipate that if such approaches were used, a similar set of findings would result.

Despite these limitations, our application of the GHI model provides further evidence supporting the hypothesis that the negative consequences of social position cluster among the socially disadvantaged. While socioeconomic gradients constitute one of the most robust findings in social and perinatal epidemiology [28], our study reveals a less known gradient towards the simultaneous occurrence of multiple adverse outcomes associated with increasing disadvantage. Income inequalities accounted for 51 and $78 \%$ of the excess risk of having 2 and 3-5 conditions, respectively, supporting their role as a fundamental cause [16]. While we provided evidence supporting the existence of a clustering of multiple adverse outcomes with increasing deprivation, we did not have appropriate longitudinal data to test the related hypothesis that, at a given level of lower social position, the occurrence of concomitant adverse outcomes would be higher among those who have been exposed longer or repeatedly to low SEP [13, 15]. Such approaches might be useful for examining specific questions around social exposures such as discrimination [54] or issues of deprivation such as the weathering hypothesis [55, 56]. Further research in this area will benefit from adopting a life-course perspective [57] and analysing longitudinal datasets.

Our findings have important implications for research and practice. From an analytic perspective, the diseasespecific model underestimates the negative impact of low SEP on health. In particular, it overlooks the fact that socially disadvantaged individuals are also affected by related conditions other than the one under investigation. 
Thus, the broad non-specific effects of SEP on health domains may be better captured by the GHI model. From a policy perspective, the understanding that low SEP is not only independently associated with various adverse outcomes but also with their simultaneous occurrence suggests that greater health gains may be achieved if investments focus on reducing the social inequities behind the health disparities rather than on tackling proximate risk factors that may hopefully prevent one but not all negative consequences of low social position $[58,59]$. It is important to clarify that the GHI model does not intend to replace disease-specific research, which is the model of choice when the interest is to unveil the mechanisms and pathways for specific and well-defined health outcomes. However, when the goal is to weigh the non-specific sequels of SEP on a general domain of health, such as mental health or reproductive health, the GHI model has clear advantages.

Acknowledgments The authors would like to thank the Maternity Experiences Study Group of the Public Health Agency of Canada's Canadian Perinatal Surveillance System who developed and implemented the MES.

Open Access This article is distributed under the terms of the Creative Commons Attribution Noncommercial License which permits any noncommercial use, distribution, and reproduction in any medium, provided the original author(s) and source are credited.

\section{References}

1. Rosen, G. (1993). A history of public health. New York: The Johns Hopkins University Press.

2. Susser, M., \& Susser, E. (1996). Choosing a future for epidemiology: I. Eras and paradigms. American Journal of Public Health, 86(5), 668-673.

3. Tesh, S. N. (1988). Hidden arguments: Political ideology, disease prevention policy. New Brunswick, NJ: Rutgers University Press.

4. Commission on the Social Determinants of Health. (2008). Closing the gap in a generation: Health equity through action on the social determinants of health. Final report of the Commission on Social Determinants of Health. Geneva: World Health Organization.

5. Berkman, L. F., \& Kawachi, I. (2000). Social epidemiology. New York: Oxford University Press.

6. O'Campo, P., \& Dunn, J. (2011). Rethinking social epidemiology: Towards a science of change. Dordecht: Springer.

7. Joseph, K. S., et al. (2007). Socioeconomic status and perinatal outcomes in a setting with universal access to essential health care services. Canadian Medical Association Journal, 177(6), 583-590.

8. Kramer, M. S., et al. (2001). Socio-economic disparities in preterm birth: causal pathways and mechanisms. Paediatric and Perinatal Epidemiology, (Suppl 2), 104-123.

9. Mortensen, L., Helweg-Larsen, K., \& Andersen, A. (2011). Socioconomic differences in perinatal health and disease. Scandanavian Journal of Public Health, $39(7 \mathrm{Suppl}), 110-114$.

10. Pickett, K., et al. (2005). The effects of racial density and income incongruity on pregnancy outcomes. Social Science and Medicine, 60, 2229-2238.
11. Pickett, K., et al. (2009). Ethnic density effects on maternal and infant health in the Millennium Cohort Study. Social Science and Medicine, 69, 1476-1483.

12. Pickett, K., \& Wilkinson, R. (2010). Inequality: an underacknowledged source of mental illness and distress. The British Journal of Psychiatry, 197, 426-428.

13. Lynch, J. W., Kaplan, G. A., \& Shema, S. J. (1997). Cumulative impact of sustained economic hardship on physical, cognitive, psychological, and social functioning. New England Journal of Medicine, 337(26), 1889-1895.

14. Aneshensel, C. S., Rutter, C. M., \& Lachenbruch, P. A. (1991). Social structure, stress and mental health: Competing conceptual and analytic models. American Sociological Review, 56, 166-178.

15. Bartley, M., Blane, D., \& Montgomery, S. (1997) Health and the life course: Why safety nets matter. British Medical Journal, 314(7088), 1194-1196.

16. Link, B. G., \& Phelan, J. (1995). Social conditions as fundamental causes of disease. Journal of Health and Social Behavior, Special No(Extra issue), 80-94.

17. Macintyre, S. (1997). The Black report and beyond: What are the issues? Social Science and Medicine, 44(6), 723-745.

18. Aneshensel, C. S. (2005). Research in mental health: Social etiology versus social consequences. Journal of Health Social Behaviour, 46(3), 221-228.

19. Lynch, J., \& Kaplan, G. (2000). Socioeconomic position. In L. F. Berkman \& I. Kawachi (Eds.), Social epidemiology (pp. 13-35). New York: Oxford University Press.

20. Cassel, J. (1976). The contribution of the social environment to host resistance: The fourth Wade Hampton Frost Lecture. American Journal of Epidemiology, 104(2), 107-123.

21. Braveman, P., Egerter, S., \& Williams, D. R. (2011). The social determinants of health: Coming of age. Annual Review of Public Health, 21(32), 381-398.

22. Syme, S. L. (2008). Reducing racial and social-class inequalities in health: The need for a new approach. Health Affairs (Millwood), 27(2), 456-459.

23. Wilkinson, R., \& Pickett, K. (2009). The spirit level: Why greater equality makes societies stronger. New York: Bloomsbury Press.

24. Kleist, P. (2007). Composite endpoints for clinical trials: Current perspectives. International Journal of Pharmaceutical Medicine, 21(3), 187-198.

25. Zweben, A., \& Cisler, R. (1996). Composite outcome measures in alcoholism treatment research: Problems and potentialities. Substance Use and Misuse, 31(13), 1783-1805.

26. Bandeen-Roche, K., et al. (1997). Latent variable regression for multiple discrete outcomes. Journal of the American Statistical Association, 92(440), 1375.

27. Horwitz, A. V., White, H. R., \& Howell-White, S. (1996). The use of multiple outcomes in stress research: A case study of gender differences in responses to marital dissolution. Journal of Health and Social Behavior, 37(3), 278-291.

28. Kramer, M. S., et al. (2000). Socio-economic disparities in pregnancy outcome: Why do the poor fare so poorly? Paediatric and Perinatal Epidemiology, 14(3), 194-210.

29. Public Health Agency of Canada. (2008). Canadian perinatal health report, 2008 edition. Ottawa: Public Health Agency of Canada.

30. Statistics Canada. (2007). Microdata User Guide-Maternity Experiences Survey 2006. Ottawa: Minister of Public Works and Government Services Canada.

31. Dzakpasu, S., et al. (2008). The Canadian maternity experiences survey: Design and methods. Journal of Obstetrics and Gynaecology, 30(3), 207-216.

32. Kingston, D., et al. (2010). Factors associated with perceived stress and stressful life events in pregnant women: Findings from 
the Canadian maternity experiences survey. Maternal and Child Health Journal, 1-11. doi:10.1007/s10995-010-0732-2.

33. Public Health Agency of Canada. (2009). Maternity experiences survey, 2006 questionnaire. Ottawa: Public Health Agency of Canada.

34. Public Health Agency of Canada. (2009). What mothers say: The Canadian maternity experiences survey. Ottawa: Public Health Agency of Canada.

35. Beydoun, H. A., et al. (2010). Intimate partner violence as a risk factor for postpartum depression among Canadian women in the maternity experience survey. Annals of Epidemiology, 20(8), 575-583.

36. Goyal, D., Gay, C., \& Lee, K. A. (2010). How much does low socioeconomic status increase the risk of prenatal and postpartum depressive symptoms in first-time mothers? Womens Health Issues, 20(2), 96-104.

37. Misra, D. P., O'Campo, P., \& Strobino, D. (2001). Testing a sociomedical model for preterm delivery. Paediatric and Perinatal Epidemiology, 15(2), 110-122.

38. Mustard, C. A., \& Roos, N. P. (1994). The relationship of prenatal care and pregnancy complications to birthweight in Winnipeg Canada. American Journal of Public Health, 84(9), $1450-1457$.

39. Savitz, D. A., et al. (2011). The epidemiology of hospitalized postpartum depression in New York state, 1995-2004. Annals of Epidemiology, 21(6), 399-406.

40. Taillieu, T., \& Brownridge, D. (2010). Violence against pregnant women: Prevalence, patterns, risk factors, theories, and directions for future research. Aggression and Violent Behavior, 15, 14-35.

41. Kramer, M. S., et al. (2001). A new and improved populationbased Canadian reference for birth weight for gestational age. Pediatrics, 108(2), E35.

42. Cox, J. L., Holden, J. M., \& Sagovsky, R. (1987). Detection of postnatal depression. Development of the 10-item Edinburgh Postnatal Depression Scale. British Journal of Psychiatry, 150, 782-786.

43. Beck, C. T., \& Gable, R. K. (2001). Comparative analysis of the performance of the Postpartum Depression Screening Scale with two other depression instruments. Nursing Research, 50(4), 242-250.

44. Murray, L., \& Carothers, A. D. (1990). The validation of the Edinburgh Post-natal Depression Scale on a community sample. British Journal of Psychiatry, 157, 288-290.

45. Statistics Canada. (1993). Violence Against Women Survey. Ottawa: Statistics Canada.
46. Statistics Canada. (2006). Census dictionary. Catalogue no. 92-566-X. 2010. Ottawa: Minister of Industry.

47. Statistics Canada. (2007). Standard geographical classification (SGC) 2006. Ottawa: Ministry of Industry.

48. SAS Institute Inc. (2008). SAS/STAT ${ }^{\circledR} 9.2$ user's guide. Cary, NC: SAS Institute Inc.

49. Zhang, J., \& Yu, K. F. (1998). What's the relative risk? A method of correcting the odds ratio in cohort studies of common outcomes. Journal of the American Medical Association, 280(19), $1690-1691$.

50. Rockhill, B., Newman, B., \& Weinberg, C. (1998). Use and misuse of population attributable fractions. American Journal of Public Health, 88(1), 15-19.

51. Urquia, M. L., \& Gagnon, A. J. (2011). Glossary: Migration and health. Journal of Epidemiology and Community Health, 65(5), 467-472.

52. Wright, E. O. (2008). Chapter 11: Logics of class analysis. In A. Lareau \& D. Conley (Eds.), Social class: How does it work?. New York: Russell Sage.

53. Blakely, T., et al. (2004). Income and mortality: The shape of the association and confounding New Zealand Census-Mortality Study, 1981-1999. International Journal of Epidemiology, 33(4), 874-883.

54. Giurgescu, C., et al. (2011). Racial discrimination and the blackwhite gap in adverse pregnancy outcomes: A review. Journal of Midwifery and Women's Health, 56(4), 362-370.

55. Geronimus, A. (2001). Understanding and eliminating racial inequalities in women's health in the United States: The role of the weathering conceptual framework. Journal of the American Medical Women's Association, 56, 1-5.

56. Geronimus, A. (1996). Black/white differences in the relationship of maternal age to birthweight: A population-based test of the weathering hypothesis. Social Science and Medicine, 42, 589-597.

57. Braveman, P., \& Barclay, C. (2009). Health disparities beginning in childhood: A life-course perspective. Pediatrics, 124(Suppl 3), S163-S175.

58. Bhatia, R., \& Katz, M. (2001). Estimation of health benefits from a local living wage ordinance. American Journal of Public Health, 91(9), 1398-1402.

59. Keherer, B. H., \& Wolin, C. M. (1979). Impact of income maintenance on low birth weight: Evidence from the gary experiment. The Journal of Human Resources, 14(4), 434-462. 